\title{
A Theoretical Framework for Teacher Incentives: Monetary, Social and Vision-Based
}

\author{
Farah Mallah $^{1}$
}

${ }^{1}$ Chicago, IL, USA

Correspondence: Farah Mallah, 1700 E $56^{\text {th }}$ St., Chicago, IL, 60637, USA. E-mail: farah_mallah@gse.harvard.edu

Received: October 23, 2018

Accepted: November 13, $2018 \quad$ Online Published: December 30, 2018

doi:10.5539/jel.v8n1p29

URL: https://doi.org/10.5539/jel.v8n1p29

\begin{abstract}
Teachers are at the heart of the education process; in attempts to improve teacher quality there has been a trend in the US and elsewhere to incentivize teachers to put in more effort. This paper presents a theoretical framework for analyzing and designing different incentive schemes informed by the structure and quality of tasks constituting the k-12 teaching profession. It focuses on the question of how policy makers and education leaders can improve teacher effort towards the outcome of interest, specifically improving student achievement. It draws on literature on incentives, goal setting theory, norms and work significance to identify three main types of incentives: (1) monetary incentives, (2) social incentives and (3) vision-based incentive. Each of the types of incentives in this paper are analyzed in light of Vroom's (1964) expectancy theory-its expectancy, valence and instrumentality - to build a theoretical framework for analyzing the potential mediating factors of each of the incentive schemes and their impact.
\end{abstract}

Keywords: incentives, expectancy, teachers, frame-work

\section{Introduction}

A series of incentive schemes have been administered in the United States in the last decade in an attempt to improve students' educational outcomes by improving teacher quality (Fryer, 2013). The focus on incentive schemes is motivated by the fact that teachers matter; a 1 standard deviation increase in teacher quality is associated with a higher math and reading achievement of $0.15-0.24$ and $0.15-0.20$ standard deviations, respectively (Rockoff, 2004; Hanushek \& Rivkin, 2005; Aaronson, Barrow, \& Sander, 2007; Kane \& Staiger, 2008, as cited in Fryer, 2013). As such, the incentive schemes usually target teachers and/or schools and link their evaluations to student outcomes. These evaluations are then linked to monetary incentives such as financial grants - an example is "Race to the Top" administered by the Obama administration - or teacher promotion, bonus, raise and/or tenure (Fryer, 2013). In both Tennessee and NYC monetary teacher incentive schemes linked to teacher evaluations had no effect on students' achievement (Freyer, 2013) (Note $1 \& 2$ ).

The ineffectiveness of multiple monetary incentives can be related to factors that make the teaching profession in k-12 schools particularly challenging. The complex nature of the teaching profession, its link to student outcomes, coupled with the significant impact of student outcomes on students' future life prospects makes this an important yet complicated case for incentivizing better teaching. In this paper, I draw on literature on incentives, goal setting theory, norms and work significance to identify three main types of incentives: (1) monetary incentives, (2) social incentives and (3) vision-based incentive. Each of the types of incentives, in this paper, are analyzed in light of Vroom's (1964) expectancy theory-its expectancy, valence and instrumentality - to build a theoretical framework for analyzing the potential mediating factors of each of the incentive schemes and their impact. This framework is informed by the challenges that define the teaching profession, and the complex nature of human motivation.

Some of the factors contributing to the challenging nature of the teaching profession include: (1) The client (student) is not the main evaluator of teacher effort/outcome. (2) Both outcome and effort are difficult to capture in the teaching profession-outcome is multifaceted, some of which is actualized in the long-run (Note 3). (3) The tasks associated with the teaching profession are complex; they require multiple inputs. (4) The link between the input (effort) and output (higher student achievement) is not clear-defining student achievement as higher 
test scores. Though these challenges exist in other sectors, their existence simultaneously may have a coupling effect that would exaggerate the challenge.

Expanding on the fourth challenge, we know there is an association between teachers and student outcomes, but it is not clear what observable characteristics of teachers lead to higher student outcomes (Rivkin, Hanushek, \& Kain, 2005; Aaronson Barrow, \& Sander, 2007; Kane \& Staiger, 2008; Rockoff et al., 2008, as cited in Fryer, 2013). As such, even if teachers are incentivized to care more about student outcomes, if they do not know how they can change their actions to improve their outcomes, the incentive would have no impact or a negative one if it asks teachers to focus on one area rather than another. The weakly defined link between teacher action and student outcomes, coupled with the added pressure of the incentives, is likely to amplify any negative consequence of a monetary incentive in the education field. Teachers are paid around the average wage of individuals with a Bachelor's degree, $\$ 55,490$ - $\$ 58,030$, (Bureau of Labor Statistics, 2017) as such a bonus of $8 \%$ (Note 4) is expected to be highly valued. In an attempt to bridge the gap between input (effort) and desired output (student test outcomes) teachers will likely resort to teaching to the test (Note 5) and cheating (Note 6). Both of those elements could lead to lower student outcomes in the long-run.

The other layer of complexity associated with incentivizing teachers is the multifaceted nature of motivation, especially in a pro-social industry. Some teachers may have entered the teaching profession intrinsically motivated. Intrinsic motivation is when individuals are driven by an inherent enjoyment or interest in the work (Ryan \& Deci, 2000). For example, some teachers may have chosen the teaching profession because they enjoy teaching and working with children. That said, other teachers may have entered the teaching profession because it provides them a source of benefit other than the work itself-they are extrinsically motivated (Ryan \& Deci, 2000). For example, some teachers may have entered the profession because of the salaries or the positive social recognition associated with it. That said, it is rarely one or the other, teachers can be both motivated intrinsically and extrinsically, but it is important to understand how those two interact with one another, and how they may strengthen or weaken the effect of the other. In this paper, the first two incentive schemes proposed are based on extrinsic motivation, while the third leans towards utilizing intrinsic motivation.

In this paper, I aim to disentangle these complexities associated with the teaching profession by building a theoretical framework that can guide future research. Unlike much of the literature and theories on teacher incentive schemes which tends to either focus on monetary incentives (e.g. Lazear, 2003; Figlio, \& Kenny, 2007) or teacher motivation (that examine other non-monetary approaches) (e.g. Carole \& Russell, 1984; Watt \& Richardson, 2015) in this paper I try to build a common framework to evaluate both monetary and non-monetary incentives, as well as examples of how such incentives can be tested and implemented.

In each section below, I present a potential intervention design, followed by theories which support hypothesis for what the mediating factors might be and how they would influence student outcomes of interest given the challenges of the teachings profession. The theories are presented with close reference to Vroom's (1964) expectancy theory. I conclude with a proposal for how the different incentives can be evaluated in the school setting. The purpose of this paper is not to summarize the literature on each of the incentive schemes. Instead it is to present a theoretical framework which can be falsified or confirmed by a series of research projects.

\section{Monetary Incentives}

Method. Teachers are given a monetary bonus of an amount deemed valuable, such that the expected benefit of exerting the effort outweighs the costs associated with it. For example, in public schools in country $x$ teachers are paid $\$ 10,000$ which is the average pay wage in the country. Given this wage, an increase of $\$ 1000$ is deemed valuable by the teachers such that they are willing to exert the effort needed to improve student test scores by an average of 5 points. This data would have to be informed by speculation based on either a smaller pilot, qualitative research, lab experiments or a mix of all three to better predict: what amount is valuable enough for the teachers to exert the effort needed to improve average student scores by the amount pre-specified (such that $\mathrm{E}[$ benefit $]=\mathrm{E}[\mathrm{cost}]$ for an average teacher)? For the purpose of developing the theoretical framework and propositions associated with this incentive, we will assume that this equilibrium can be achieved on average and that policy makers can identify this equilibrium.

Mediators. According to Vroom's (1964) expectancy theory, people act in such a way that maximizes their expected utility from the outcome (as cited by Bonner \& Sprinkler, 2002). There are three main elements according to Vroom (1964) which determine how an individual will behave: expectancy, valence and instrumentality (as cited in Lunenburg, 2011). Expectancy is the likelihood that the effort will lead to the performance that is rewarded; valence is the value an individual has for the reward proposed; instrumentality is the likelihood that the performance will lead to the reward (as cited in Lunenburg, 2011). 
The valence of the rewards can be further explained by the Agency Theory. Agency Theory suggests that individuals seek more wealth and leisure (Bonner \& Sprinkler, 2002). As such, unless effort will lead to higher wealth, individuals would rather exert less effort and have more leisure (Bonner \& Sprinkler, 2002). That said, people value additional monetary incentives differently. Considering the complexity of the teaching profession, the effort needed for one point increase in average student test scores is probably high. Assuming we identified the level at which teachers' expected benefit from the additional amount of wealth, E(benefit), is equal to teachers' expected effort necessary to increase student test scores by the specific amount, E(cost), we should expect an increase in student outcomes. In light of this theory, the effectiveness of the monetary incentive depends on how much value teachers will place on the incentive; its valence and level of increase in wealth compared to the increase in effort. Keeping in mind the value of the incentive is discounted depending on when in time it is given (Chabris, Laibson, \& Schuldt, 2010).

Proposition 1a: If teachers perceive expected benefit of the incentive is equal to or greater than the expected cost of additional effort, teacher performance-pay schemes will increase teacher effort towards the outcome linked to the incentive.

Proposition 1b: The more complex a teacher's task is (e.g. the fewer the resources) the higher the cost associated with additional effort, and the less effective the monetary incentive is.

The agency theory has explanatory power, but fails to predict the payment strategy of companies. It over estimates the likelihood of companies using performance based interventions (Larkin, Pierce, \& Gino, 2012). In this paper, I propose there are two other levers to consider expectancy and instrumentality which agency theory fails to consider. Further, Larkin, Pierce \& Gino (2012) propose psychological factors explained by social comparison theory and over confidence can help explain why performance-based measures are not as common as expected by Agency Theory. I will refer to those two theories next in relation to the instrumentality and expectancy of the incentive schemes in light of the teaching profession.

The likelihood of receiving the monetary incentive if the outcome is met matters when deciding to exert the necessary effort. In other words, if a teacher is able to improve student outcomes as defined by the incentive scheme, the likelihood of him/her receiving the incentive (instrumentality) matters. Both the valance and the instrumentality of the reward can be controlled. Instrumentality can be strengthened by having a clear rubric on which the teachers are evaluated. Linking teacher performance-pay to student test-scores can be a straightforward way to improving the instrumentality of the measure.

That said, additional effort is needed to insure teachers perceive this process as "fair" especially in the school setting where teachers work in the same office spaces usually, and have frequent interactions with their colleagues within a relatively small organization. According to social comparison theory, individuals evaluate their ability and pay relative to others (Festinger, 1954, as cited in Larkin, Pierce, \& Gino, 2012). As such, it is important that they perceive the process as fair. If they perceive it as unfair, it is likely to increase costs associated with higher levels of conflict between employees, lower effort, higher likelihood of unethical behavior and lower satisfaction levels (Greenberg, 1988; Cohn et al., 2012; Nosenzo, 2010; Cropanzano, Rupp, \& Byrne, 2003; Pruitt \& Kimmel, 1977; Gino \& Pierce, 2010; Edelman \& Larkin, 2009; Faulkender \& Yang, 2010; DiPrete, Eirich, \& Pittinsky, 2008, as cited in Larkin, Pierce, \& Gino, 2012). It is important to note here that in the education sector this is hard to achieve because there is large between school variation in student and teacher compositions, as well as within school variation between classrooms (for example Advanced Placement classes compared to other classes) (See Douglas (2010) for a discussion of within and between school variation in school compositions by socioeconomic status).

Proposition 2a: Using a clear outcome based indicator on which performance-pay is based is likely to improve teachers' perception of the fairness of the measure, leading to higher teacher effort and student outcomes.

Proposition 2b: Using an outcome based indicator within a setting with varied classroom and teacher compositions is likely to worsen teachers' perception of fairness of the measure, leading to lower teacher effort and student outcomes.

Compared to valence and instrumentality, expectancy is harder to manipulate and predict. Teacher expectancy is teachers' perception of the likelihood the effort they put in class is going to lead to higher student outcomes. By helping students cheat, designing easier exams, teaching for the test, teachers are increasing the likelihood that their effort will lead to higher student outcomes as currently measured - by exam results. Other methods, such as more formative tests, are not as clearly linked to the outcome as those which may have negative repercussions on learning, such as cheating. 
Bonner and Sprinkler (2002) further argue that expectancy depends on theories of self-efficacy; such that higher levels of self-efficacy are likely to strengthen the link between effort and the desired outcome. It can also improve self-efficacy such that incentives signal to individuals that they are capable of achieving more and as such increases how much effort they are willing to put in. Interestingly, Larkin, Pierce \& Gino (2012) suggest, in reference to studies done on overconfidence bias (Weinstein, 1980; Taylor \& Brown, 1988, as cited in Larkin, Pierce, \& Gino, 2012) that people tend to over predict their abilities. This bias, in this case, is good since it increases the likelihood of teachers believing they can achieve the goal they set to achieve to receive the specific pay. That said, if they repeatedly fail at doing so, this may demotivate them and decrease their effort.

Proposition 3a: teachers with higher self-efficacy are likely to exert more effort in improving student outcomes, leading to higher student outcomes.

Proposition 3b: teachers who over predict their ability, if they fail to achieve their expectation multiple times, will be demotivated leading to lower long-term levels of effort.

Incentives may change a teacher's goal (Bonner \& Sprinkler, 2002). An incentive can also be seen as a goal in itself. Since incentives tend to have a clear specific outcome/goal, we expect teacher goals to adopt that same specificity. In addition, they are likely to adopt the same difficulty level associated with the incentive. If the goal set by the incentive proposes a better difficulty level and specificity compared to teachers' previous goals, then it is likely to improve performance. Higher goal difficulty levels (until a specific point) and specificity are associated with higher performance levels (Bonner \& Sprinkler, 2002).

Proposition 4: Specific and difficult outcome based incentives are likely to improve teacher goals, leading to higher teacher effort and student outcomes.

There are multiple factors specific to the teaching profession which would weaken these mediating factors linking incentives to higher performance, besides the low expectancy probability. One of which is the complexity of the task. Task complexity is higher if it requires more processing and has less structure (Campbell, 1988; Wood, 1986, as cited in Bonner \& Sprinkler, 2002). We can classify the tasks associated with achieving a specific student outcome are complex. Different students have varied needs depending on their educational and cultural backgrounds, as well as their individual learning differences. This variation means that teachers need to find creative ways to deliver a lesson to reach the highest number of students. Further, there is no set way of delivering a lesson, there are multiple ways and teachers need to figure out which way suits their classrooms best which is usually a difficult choice to make. These elements make teaching less structured and require high processing levels. Task complexity increases the cost associated with more effort, as such higher valence would be required. It also increases the necessary level of skill and self-efficacy teachers would need to possess to achieve the outcome (Bonner \& Sprinkler, 2002). In addition, task complexity increases the level of stress associated with trying to achieve the outcome set which may result in "chocking" at the job-lowering performance levels(Note 7) (Bonner \& Sprinkler, 2002; Kamenica, 2012).

Proposition 5a: The task complexity associated with the teaching profession increases the level of self-efficacy required to achieve the same outcome.

Proposition 5b: The task complexity associated with the teaching profession weakens the link between input (teacher effort) and output (student test scores)—its expectancy_leading to lower effort to achieve the outcome.

Another factor to consider is imprecise performance measures in the teaching profession. The imprecision is a product of three potential elements: (1) a good teacher is not only a teacher that improves students' academic performance, he/she is also tasked to improve students' socio-emotional skills. (2) Improving students' academic performance is a product of multiple tasks teachers need to perform, all of which vary depending on students' needs and the link between observable actions and their ability to improve student outcomes is still not clear. (3) The impact of a teacher's positive or negative teaching practices may be realized in the long; for example, a teacher who teaches for the test may improve student scores in the short-run, but would negatively impact their learning and academic achievement in the long-run (Note 8).

Holmstorm and Milgrom (1991) suggest that a flat-rate would be better than measuring teacher performance on one, limited, dimension of student achievement. In having imprecise measures, the effectiveness of the reward on the outcome becomes much lower (Holmstorm \& Milgrom, 1991). Bonner and Sprinkler (2002) suggest this happens because in linking the incentive to a specific task, individuals are likely to focus on that task at the cost of other tasks decreasing overall performance (also discussed by Lazear \& Gibbs, 2015). 
Proposition 6: given the imprecision of student and teacher outcome measurements, teacher effort and student outcomes are higher with a flat-rate pay structure compared to a performance-pay structure.

When hypothesizing the impact of incentives on a profession such as teaching which is usually considered a prosocial profession - in service of others - it is important to consider how a monetary incentive can taint the way teachers perceive their profession as well as how others perceive them. Benabou \& Tirole (2006) suggest that if individuals care about what others think of them, and they are performing a pro-social act because they believe that it will result in others perceiving them as altruistic, a monetary incentive in this setting will reduce the effectiveness of the pro-social act as an altruism signal to others. For example, if teachers provided student with additional support in after school hours and provided them with additional worksheets because he/she wanted to signal to the students and/or teachers that he/she is a good teacher who cares, then providing a monetary incentive may taint the act as a selfish attempt to get more money.

Further, teachers may be getting a level of satisfaction from doing something "good" for the students, or may see such actions as their responsibility and in not doing them they would feel guilty. Attaching money to these actions is likely to change the way teachers perceive these actions. It might signal that only if they wanted the additional money would they do those actions. They would no longer enjoy doing them because they no longer serve their need to perceive themselves and their work as "good" and feel like it is something they have to do for the money. Kahneman and Knetch (1992) find that the level of "moral satisfaction" individuals receive from an action can predict their willingness to pay for it. Further, in a series of experiments in which participants were exposed to money in various ways, they found that exposure to money reduces the likelihood of individuals helping others and working in teams (Vohs et al., 2006).

Individuals' pre-dispositions, why they do what they do, matters to predicting the impact of a monetary incentive. Individuals who perform the act regardless of the monetary incentives are those who are more likely to experience crowding out when monetary incentive is provided (Benabou \& Tirole, 2006). Melltorm and Johannesson (2005) found that women were much more likely to provide blood donations compared to men (52\% compared to $28 \%$ ). When provided with an incentive, men's contribution did not change (increase was not statistically significant) while women's contribution dropped to $30 \%$. Interestingly, women's contribution increased when they were told they can donate the monetary incentive they received to a cancer related charity (to 53\%) (Melltorm \& Johannesson, 2005). In support of this theory in the teaching profession, in a survey administered to teachers in the UK, $80 \%$ of the respondents chose "Enjoy working with children and young people" as a reason for why they wanted to become teachers, and $74 \%$ chose "I want to make a difference" as one of the reasons (ATL, 2017). This suggests that teachers may be motivated by pro-social aspects of the teaching profession that risk being crowded out with monetary incentives.

Proposition 7a: Given the pro-social nature of the teaching profession, providing a monetary incentive is likely to crowd-out pro-social motives to increasing effort to improve student outcomes, leading to lower teacher effort and lower student outcomes.

Proposition 7b: Teachers who used to exert higher than average levels of effort before the incentive scheme are likely to decrease their effort when a monetary incentive is applied.

Considering the valence, expectancy and instrumentality of a monetary helps inform our intervention design, as well as the evaluation of its effectiveness. The valence of an incentive is a product of how complex a teacher's task is, current salary and level of pro-social motives before implementing the incentive. The expectancy of an incentive depends on teachers' self-efficacy, precision of measure and task complexity as it relates to the link between teacher effort and outcome. The instrumentality, of an incentive depends on the clarity of the outcome standard on which a teacher is evaluated, as well as the variation between and within schools in classroom composition. Both those elements contribute to teachers' perception of fairness which is likely to affect their effort. Figure 1 on the next page summarizes the hypothesis put forth in this section. 


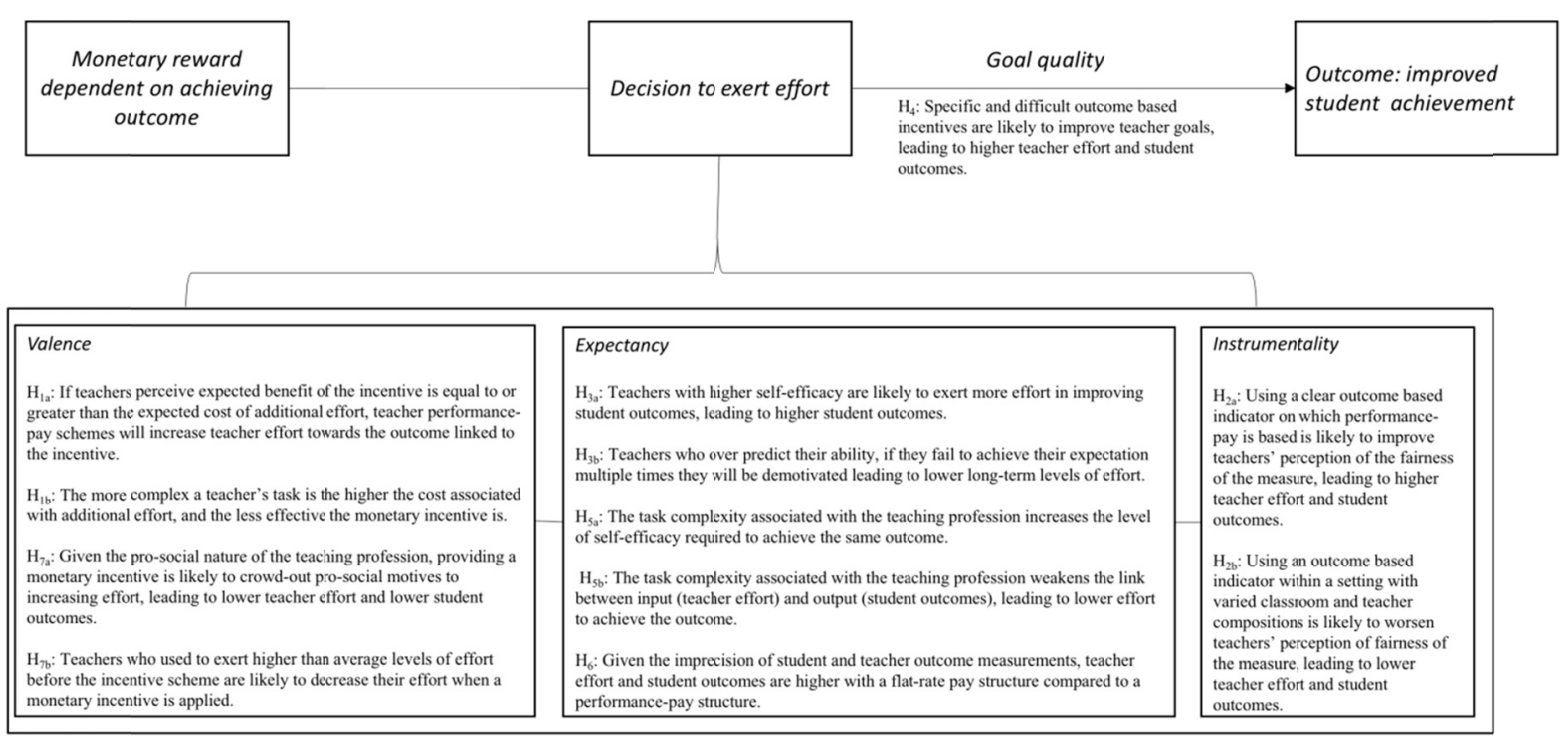

Figure 1. Monetary incentives: summary of hypothesis $(H)$ based on Vroom's expectancy framework

\section{Social Incentive}

The pro-social nature of the teaching profession lends itself to other types of rewards that would emphasize or help spread a positive social norm. In this section, I explore what mediators we expect to operate in an incentive scheme that benefits from social norms. I propose two studies through which we can evaluate the effectiveness of social incentives. In the first study the outcome is the same as that in the monetary incentive study proposition (a pre-specified level of improvement in student test-scores). In the second study the outcome on which receiving the incentive is dependent is more loosely defined and would be a composite measure dependent on how an "ideal" teacher is defined. The first study varies on one dimension compared to the monetary incentive proposed in Section I, while the second study varies on multiple dimensions.

Method-Study 1: Teachers who are able to improve student test-scores "significantly" are awarded in front of all other teachers and students a medal titled "great teacher of the year". For example, teachers who improve student test-scores by 10 percentage points are awarded "great teacher of the year" in an end of year celebration of teachers.

Method-Study 2. Teachers who portray "ideal" teacher qualities are awarded a medal titled "great teacher of the year" in front of all other teachers and students. For example, a school might describe an "ideal" teacher as one who supports other teachers and his/her students to excel; as well as improves student test scores. The teacher's level of support of teachers and students can be determined by having other teachers nominate a teacher who has supported them and the students can be asked to nominate a teacher as well. Based on a composite of the three indicators, the ideal teacher(s) is chosen and awarded "great teacher of the year" medal in an end of year celebration with students and teachers.

Mediators. In study 1, using expectancy theory to hypothesize the potential impact of such an incentive system, the effectiveness of the incentive system could be analyzed in light of three elements: valence, expectancy and instrumentality (Vroom, 1964). Valence here depends on how much value teachers have for the way other teachers and students perceive them. Expectancy and instrumentality, though, will be similar to the case of the monetary incentives such that they will depend on individual's self-efficacy (belief in ability to achieve the goal) and how clearly the system defines the cut-off above which a teacher would receive the reward. That said, in this case the expectancy may be weaker given the nature of social rewards. Social rewards are valued more when they are more selective, but the more selective they are the less likely the effort put in will lead to receiving the reward.

Study 1 is likely to result in some of the similar issues discussed under monetary incentives because we are still defining a great teacher by one dimension only—students' test scores. Those issues include less than optimal focus on other elements of a students' development such as socio-emotional skills which are not captured by the incentive scheme, in addition to encouraging activities that would lead to negative repercussions on student achievement such as cheating and teaching for the test. It could also crowd-out teacher effort by changing the 
motive for the action such that it becomes for recognition rather than altruism (Benabou \& Tirole, 2006). As a result of these elements, propositions $5 \mathrm{a}, 5 \mathrm{~b}$ and 6 are likely to apply here as well, given the complex nature of the teaching profession and imprecise measurement.

Proposition 1: Regardless of the type of incentive, linking the incentive to test scores (one dimension of the teaching profession) is likely to lead to propositions $5 a, 5 b$ and 6 .

In study 2 , on the other hand, the valence and instrumentality of the reward would be similar to that in study 1 , while the expectancy would differ. Given that in study 2 the elements by which the teacher is evaluated on are multiple and subjective, this might weaken the link between teacher's effort and the likelihood of receiving the evaluation desired by the award committee (expectancy). It can also lead to teachers perceiving the award as "unfair" as suggested earlier based on the social comparison theory (Larkin, Pierce, \& Gino, 2012). That said, this can be improved by clearly defining the evaluation criteria and including multiple voices, for example: students', administrations' as well as fellow teachers' evaluations of the teacher, coupled with improvements in student outcomes on exams. The advantage of this method is that it avoids some of the gaming the system elements which are present in study 1 and the monetary incentive because the outcome is no longer one-dimension. In addition, the subjective ratings by principals were found to strongly correlate with value-added measures of teacher effectiveness in both high-stakes and low-stakes settings for teacher evaluation (Grissom \& Loeb, 2017).

Proposition 2a: Linking the social award to a clearly defined multi-dimensional criteria is likely to improve student outcomes compared to linking the award to one-dimension, because it avoids overweighting one-dimension at the cost of others.

Proposition 2b: A social reward based on multiple subjective dimensions is likely to decrease teacher's perception of "fairness' of the reward.

Proposition 2c: A social reward based on multiple subjective dimensions is likely to weaken the expectancy of the incentive-the link between the input (effort) and output (outcomes on which the reward system is based).

Proposition 3a: The fewer the number of social reward recipients, the less likely receiving the reward is perceived, weakening the instrumentality of the reward.

Proposition 3b: The fewer the number of social reward recipients, the higher the value associated with getting the reward.

Both study 1 and 2 increase the observability of teacher outcomes. Enhancing the observability of a reputation enhancing behavior can increase the valence of performing the behavior (Rogers, Goldstein, \& Fox, 2018). Delmas and Lessem (2014) find that making the energy consumption of individuals living in a residence hall public reduced energy consumption by $20 \%$. In another intervention, Rogers, Ternovskia and Yoelib (2016) found that individuals were more likely to vote when sent a message that mentions a potential follow up to check if they had voted. Giving the reward to teachers in a public setting makes their past behaviors observable to others. In addition, in study 2, the data collection that happens in order to choose the teachers to be awarded may make the teachers more aware of others' observations of their behavior including students and other teachers whose evaluations are used to inform which teachers will receive the award. We can also expect that enhanced observability would have a bigger effect in a smaller organizational setting such as one school, and a job that involves a lot of social interactions.

Proposition 4a: An incentive based on subjective evaluations of teachers increases the observability of the actions made by the teacher, increasing the cost associated with not adhering to the evaluation criteria, leading to higher teacher effort.

Proposition 4b: Awards given in public settings increase the observability of teacher outcomes increasing the benefits associated with receiving the award.

Proposition 4c: In smaller schools, observability is higher, as such social awards are more effective.

Both studies work to better define the norm for what a "great" teacher looks like. There is limited literature on how norms are created, but there is literature on how using descriptive norms can influence people's behavior. That said, this literature is limited to "simple" acts since they are the easiest to measure an impact on. In a study aiming to encourage hotel guests to reuse their towels instead of having them cleaned on a daily basis, they found that adding a descriptive norm asking the guest to join their fellow guests, $75 \%$ of whom have participated, increased the participation rate by $6 \%$ (Goldstein, Cialdini, \& Griskevicius, 2008). They also find that the more 
proximate the reference group mentioned in the descriptive norm is, the more significant of an effect it had (Goldstein, Cialdini, \& Griskevicius, 2008). We find similar results in other descriptive norm interventions (Rogers, Goldstein, \& Fox, 2018) (Note 9). In these examples, people's perception of what is a "right action' changed, similarly, we expect teachers' perceptions of who is a "good teacher' to change. Further, given the social context of schools it is likely that descriptive norms, if effective in changing perceptions, will have a stronger effect given high observability of others' actions.

Proposition 5a: Social awards provide a descriptive norm of what it means to be a good teacher which is likely to change teachers' perceptions of what it means for them to be good teachers. Individual teachers would then seek this new norm as their goal.

Proposition 5b: Social awards provide a descriptive norm of what it means to be a good teacher which is likely to change the collective perception of what it means to be a good teacher, this creates collective pressure to adhere to this norm, coupled with high observability, this is likely to increase teacher effort to adhere to the norm.

Social awards activate a number of similar mediators compared to those associated with monetary incentives. Those mediators include self-efficacy, goal improvement, and task complexity. In addition to these mediators, the effect of social awards depends on its influence on social norms associated with being a good teacher, as well as the observability of teacher effort and outcome. A summary of the hypothesis is presented in Figure 2 on the next page in relation to Vroom's (1964) theory.

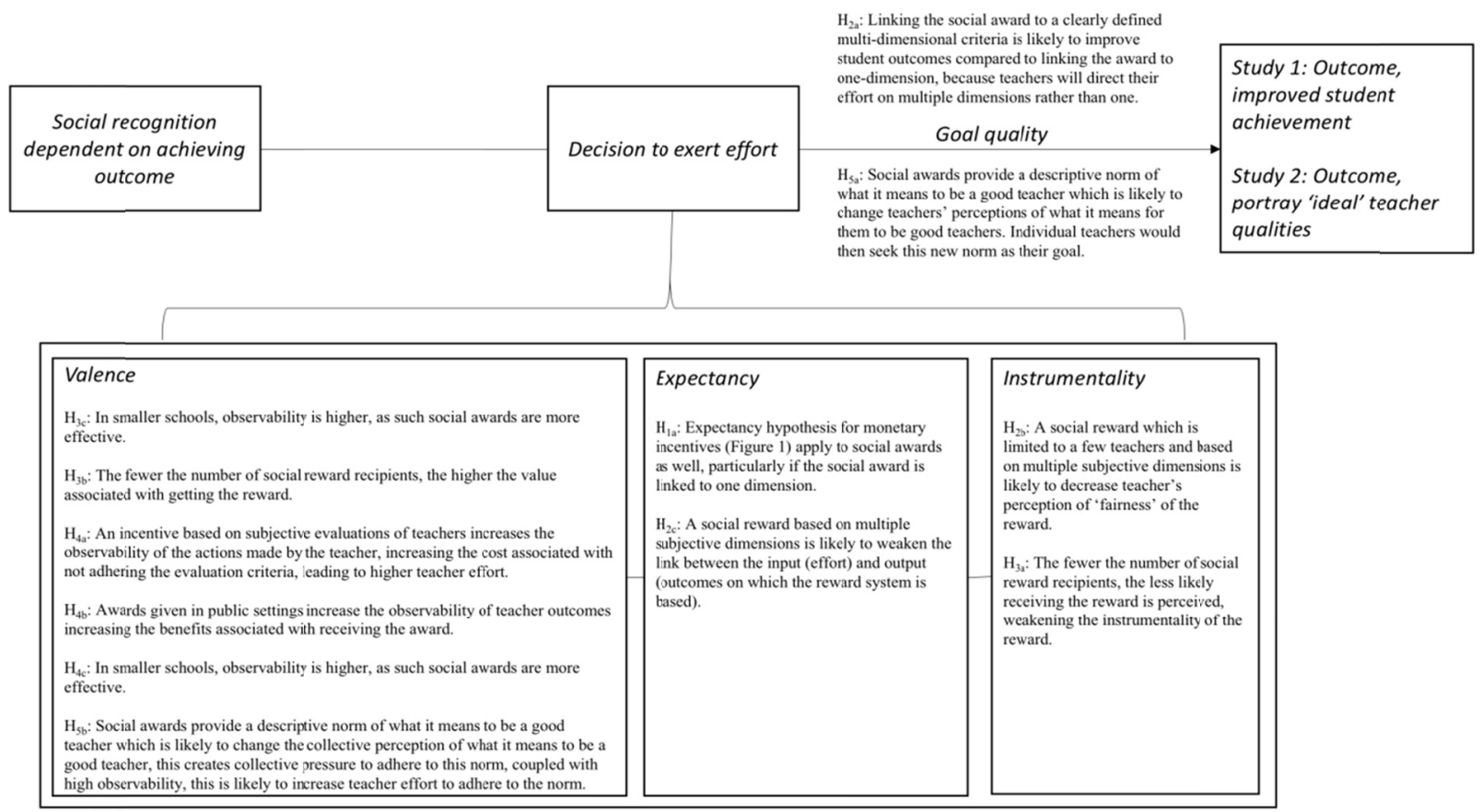

Figure 2. Social reward: summary of hypothesis based on Vroom's expectancy framework (Note 10)

\section{Vision Based Incentive}

Method. Teachers at the beginning of the year are motivated by a discussion on the importance of the teaching profession followed by an exercise in which teachers are encouraged to write their own visions for their students (what they want their students to achieve). They are encouraged to be as specific as possible and include achievable goals to reaching this vision. The teachers then meet on a monthly basis to reflect on their vision and their progress towards achieving it. Evaluators and observers also refer to teachers' student vision and self-set goals when providing them with feedback.

Mediators. This incentive scheme varies significantly compared to the previous two in that the goal is set by the teachers themselves rather than assigned. It also includes no physical reward. It depends instead on three main theory backed mediators: goal-setting, soft commitment, and significance theory.

In having the teachers set their own goals the goal is likely to better align with a teacher's perceived ability and 
as such the likelihood of achieving it with effort (expectancy) increases (Locke \& Latham, 2002). This also suggests that teachers with higher self-efficacy are likely to set more difficult goals. While teacher-training can improve teachers' abilities to achieve their goal. That said, teachers' individually set goals might not align with the goals that maximize students' achievement (academic and/or socio-emotional skills). Seits and Latham (2000) find that when the goals of individuals align with the group goal to maximize performance, the performance of the group improves. In light of this, the effectiveness of self-set goals at leading to the desired outcome is dependent on how closely self-set teacher goals align with the institutional goals.

Proposition 1a: Teachers' perception of their ability to achieve a goal if they put in the effort (expectancy) is higher when the goal is self-set rather than assigned.

Proposition 1b: Teachers with higher self-efficacy are likely to set more difficult goals.

Proposition 1c: Individualized teacher training/mentorship can help equip teachers to achieve their self-set vision for the students.

Proposition 2a: The more aligned teachers' self-set goals are with the goal of the school to improve student test-scores, the more likely the average performance of teachers at that school is to improve and lead to higher student test-scores.

If the individual goal is receiving a "greedy' incentive (monetary or social recognition), then it is likely not to align with the group goals. According to Locke and Latham (2002), self-enhancing goals negatively impact group performance. In this incentive scheme, the goals are framed as goals for the students rather than teacher goals (e.g. receiving a bonus, social recognition or promotion). In this case, we expect to see more alignment between teacher self-set goal and institutional (school) goals, than in the case of social rewards and monetary incentives.

Proposition 2b: Teacher and school goals are more likely to align if teacher goals are framed as their goals for the students rather than themselves.

Proposition 2c: Social awards and monetary incentives lead to "greedy' teacher goals, which are less likely to align with the institutional goal to improve students' achievement.

Setting the goal and sharing it with others, also increases the level of commitment the teachers have to achieving the goal. Soft commitment - a commitment that does not entail any objective penalty for not following through - is likely to result in psychological costs in the form of harming self-image as well as reputation among others (Bryan, Karlan, \& Nelson, 2010). Multiple experiments in the field suggest people demand soft commitments and that they have an impact on behavior. In a study, they found that asking individuals to decide what their future self will watch increases the number of "virtuous" movies chosen compared to individuals who decided what they will watch sequentially, day-by-day (Read, Loewenstein, \& Kalyanaraman, 1999). Similar, providing students with the option to set and commit to their own deadlines, improved their performance (Ariely \& Wertenbroch, 2002, as cited in Bryan, Karlan, \& Nelson, 2010).

Proposition 3: Teachers sharing their self-set goal with other teachers, mentor and school leadership creates a soft-commitment for teachers to adhere to and progress on the goal set. This increases the likelihood of achieving the goal.

Further Mento, Locke, and Klein (1992) research suggests that goals become a reference point, on which satisfaction depends. This means that teachers will start referring to the goals they set for themselves to evaluate their own success, seeking to feel satisfied by achieving the goal. This can lead to more satisfied teachers, with lower outcomes if the goal set is low. But it could also be a source of value that motivates teachers to achieve the goal. Having teachers reflect on their goals with other teachers, and share it with school leadership, mentor and other teachers, may help insure that teachers are constantly raising their goals for their students. This decreases the likelihood of having teachers satisfied with low levels of student outcome.

Proposition 4a: Teachers' self-set goal will become a reference point, on which their satisfaction and positive perception of self depends. This will be their source of motivation to achieving the goal.

Proposition 4b: Teachers self-set goals for their students will be lower than the institutional (or school) goal because they are motivated to set a lower goal to achieve it and be satisfied with lower effort.

Proposition 4c: The more times teachers reflect in groups on their self-set goals and share it with third-parties the more likely they are to set difficult and specific goals.

The emphasis on student vision, on the other hand, is likely to increase teacher's sense of task significance. Hackman and Oldham (1976) define job satisfaction as "The degree to which a job has a substantial impact on 
the lives or work of other people - whether in the immediate organization or in the external environment" (p.396). In their study, they find that employees who perceive their tasks as high in significance were likely to perform higher at their job (Hackman \& Oldham, 1976). Grant (2008) found that when job significance is highlighted in multiple settings - life guards and callers trying to get alumni donations - job performance improved. The impact was great on those who had "prosocial values" - those who prior to the intervention stated that it is important for them to serve others; as well as those who were less "Conscientious"-less organized and goal oriented (Grant, 2008).

Proposition 5: Encouraging teachers to make salient the impact of their job on the students by having them set a vision for their students and place themselves as active participants in achieving this goal will increase the benefit for teachers associated with exerting effort.

Proposition 6: The impact of highlighting teachers' work significance varies by the degree of pro-social values and conscientiousness among teachers.

The self-assigned nature of the goal in this incentive and the dependence on an intrinsic award differentiates it from the previous two incentive structures. That said, it can still be analyzed in terms of Vroom's (1964) expectancy theory. The valence of the incentive is dependent in this case on the intrinsic benefit of achieving a goal and in making salient the significance of the work. The expectancy is dependent on teachers' self-efficacy and training. In general, we expect the expectancy to be higher when the goal is self-set. On the other hand, the instrumentality of the reward was not discussed in this section because if the benefit is intrinsic then it is almost certain that individuals perceive once the goal is achieved the intrinsic benefit will be gained (it does not require a third party which may not be trusted). Much of this section was focused instead on the quality of the goals the teachers would self-set, which is not clear. This lack of clarity lends this incentive scheme to testing in the field to better understand the impact of a vision-based incentive. Figure 3 on the next page summarizes the discussion in this section, and contextualizes it in Vroom's (1964) expectancy theory.

\section{Theory and application}

The propositions presented in this paper lend themselves to research to gain a better understanding of the impact of different incentive schemes on the teaching profession. The three incentive schemes proposed can be evaluated in charter schools in the US given the relatively high level of autonomy Charter schools have over teacher incentives and evaluations. The schools can be randomly selected and assigned to the different incentive schemes. It is unlikely that all hypothesis can be tested in one intervention, and given that the randomization will have to happen at the school level we would need a large number of schools to test all three incentives. Instead, I propose using this paper as a theoretical model to test one incentive scheme and evaluate the impact of this incentive, while collecting data on the mediating factors which can help explain the results and build a stronger theoretical framework.

The type of data collected will vary depending on the research questions of interest. In general, it may be helpful to consider including three main elements in the data collection plan: (1) teachers' dispositions before and after the incentive (e.g. prosocial, conscientiousness, importance of others' perception, reasons for why they have chosen the teaching profession). (2) Teacher effort either in the form of self-reporting or an outside, third party, evaluator. (3) Student achievement (teacher outcome) calculated as a composite measure which includes student test scores on tests linked to the incentive, as well as those which were not, coupled with measures of student mindsets and socioemotional skills. It is important given the nature of the teaching profession to separate effort from outcome since teacher effort may not necessarily lead to higher student outcomes. 


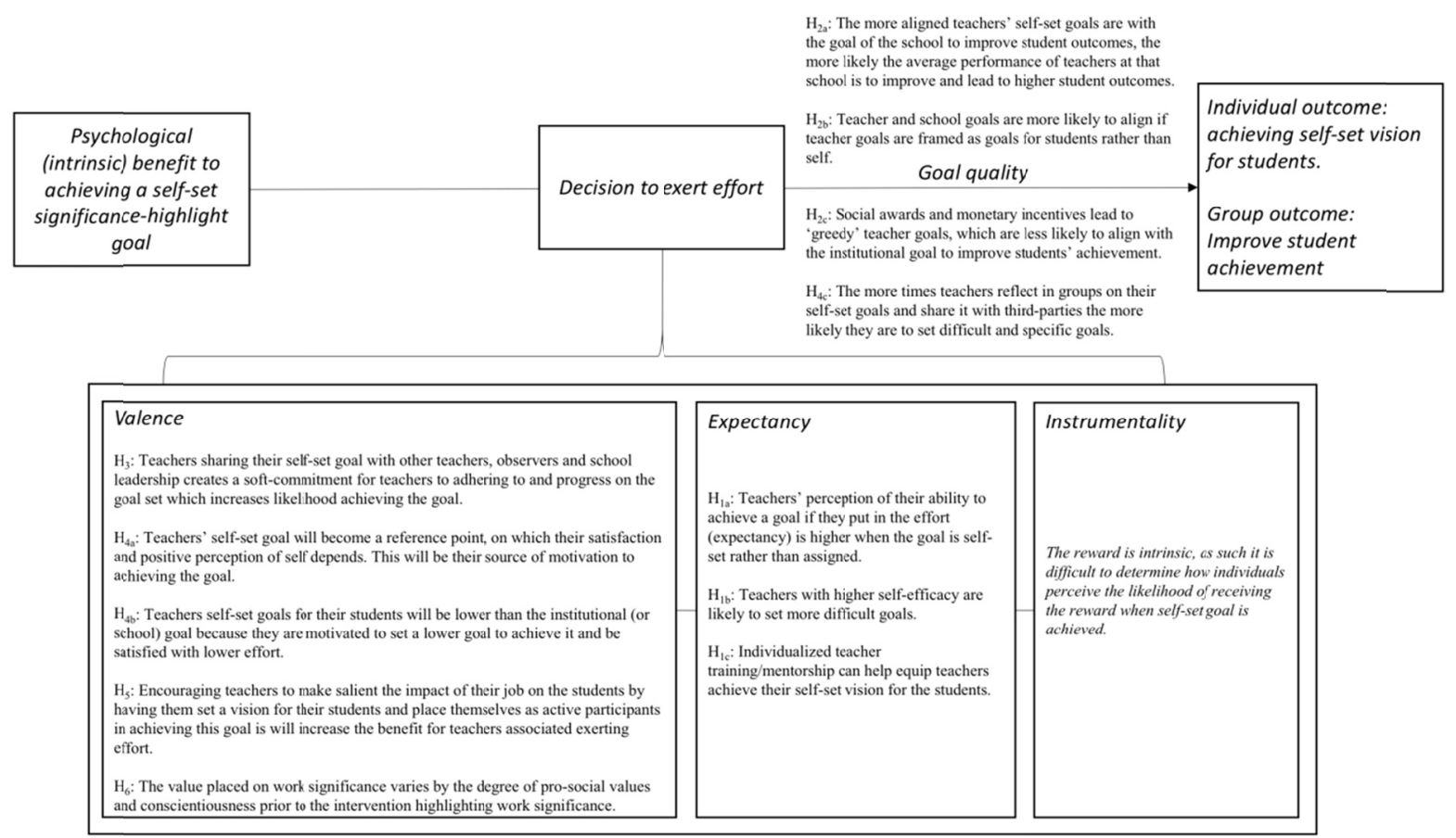

Figure 3. Vision-based incentive: summary of hypothesis based on Vroom's expectancy framework

The complexity of the teaching profession presents a challenge to the application of incentive and motivation theories, which are usually based on findings in simpler contexts. This complexity presents an opportunity for learning. A theoretical framework, such as the one presented in this paper, can help inform and advance the learning process by highlighting the potential mediating factors which influence the decision of a teacher to exert effort and the link between this effort and outcome. The main mediating factors informing a teacher's decision to exert effort are the valence of the reward, the expectancy that effort will lead to outcome and its instrumentality - likelihood of receiving the reward if the outcome is achieved (Vroom 1964). Each one of those elements are affected differently given the type of the incentive. The valence seems to vary most from one incentive to another. While following a teacher's decision to exert effort, the effectiveness of this effort is influenced by the quality of the goal (based on goal-setting theory).

There is limited literature on what incentives can best improve teacher effort and consequently, teacher quality and student outcomes. In this paper, I attempted to bring together various literature on incentives and motivation to build a common theoretical framework on which other interventions and evaluations can be built. Such a model also aims to highlight some of the assumptions made by proponents of teacher incentive schemes. By highlighting these assumptions, we can better critique and build on previous work on teacher incentivization and motivation.

\section{Notes}

Note 1 . When considering the impact, we need to keep in mind that it is highly influenced by the way the incentive scheme was designed. Further, in NYC it was a randomized control trial as such we can assume causal relation, but in Tennessee it was based on observational data. (Fryer, 2013)

Note 2. In India performance-based incentives were found to be effective, and the gains transferred to higher scores on other tests not linked to the performance pay scheme. That said, those effects do not seem to last in the long-run where students in treatment schools did not experience any gains in test scores compared to students in control schools after 5 years who remain in the program for five years. (Muralidharan, 2012)

Note 3. Larkin, Pierce \& Gino (2012) suggest that when effort is not observable, but outcome is, performance-pay is usually used. In this case, both effort and outcome are difficult to observe. This in itself makes the process of linking performance outcomes to pay in the teaching profession more challenging.

Note 4. In Tennessee pilot, the bonus amount was equivalent to $8 \%$ of teacher salaries, and in NYC intervention it was equivalent to around $5 \%$ of teacher salaries. (Fryer, 2013) 
Note 5. This was observed in the case of performance-based pay in Kenya (Glewwe, P., Ilias, N., \& Kremer, M., 2010)

Note 6. Jacob and Levitt (2003) found that cheating levels in schools that performed below average were associated with changes in incentive schemes in Chicago Public Schools.

Note 7. Literature on "chocking" tends to be limited to lab experiments, when tested in a workforce setting, the results are mixed. (Kamenica, 2012)

Note 8. Negative long-term impact on precision measurement is described by Lazear \& Gibbs (2015).

Note 9. The impact of the descriptive norms is highly dependent on the group identity and if the group actually adheres to the positive norm that is described/motivated (Rogers, Goldstein \& Fox, 2018)

Note 10. Specifically includes elements that differ from monetary incentive mediators

Note 11. Tyack \& Cuban (1995) suggest institutional goals of education tend to transfer and be viewed very differently at the classroom level. According to Tyack \& Cuban (1995) part of the reason this happened is that the goals set by the institution were vague, for example "reconstruction" without explaining what this really meant in the education field. That said, the underlying goal was always improving student outcomes, the method just varied. In the method proposed in this section, I am suggesting the broader goal of improving student outcomes may be similar but its application may differ, and this difference may be a point of strength or weakness. As such, this method lends itself to an important research question.

\section{References}

Ames, C., \& Ames, R. (1984). Systems of Student and Teacher Motivation: Toward a Qualitative Definition. Journal of Educational Psychology, 76(4), 535-56. https://doi.org/10.1037/0022-0663.76.4.535

ATL National Education Union. (2017). New teachers already demotivated about teaching at the start of their careers. $\quad$ Retrieved from https:/www.atl.org.uk/latest/new-teachers-already-demotivated-about-teaching-start-their-careers

Bénabou, R., \& Tirole, J. (2006). Incentives and prosocial behavior. American Economic Review, 96(5), 1652-1678. https://doi.org/10.1257/aer.96.5.1652

Bonner, S. E., \& Sprinkle, G. B. (2002). The effects of monetary incentives on effort and task performance: theories, evidence, and a framework for research. Accounting, Organizations and Society, 27(4-5), 303-345. https://doi.org/10.1016/S0361-3682(01)00052-6

Bryan, G., Karlan, D., \& Nelson, S. (2010). Commitment devices. Annu. Rev. Econ., 2(1), $671-698$. https://doi.org/10.1146/annurev.economics.102308.124324

Chabris, C. F., Laibson, D. I., \& Schuldt, J. P. (2010). Intertemporal choice. In Behavioural and Experimental Economics (pp. 168-177). Palgrave Macmillan, London. https://doi.org/10.1057/9780230280786_22

Delmas, M. A., \& Lessem, N. (2014). Saving power to conserve your reputation? The effectiveness of private versus public information. Journal of Environmental Economics and Management, 67(3), 353-370. https://doi.org/10.1016/j.jeem.2013.12.009

Figlio \& Kenny. (2007). Individual teacher incentives and student performance. Journal of Public Economics, 91(5), 901-914.

Fryer, R. G. (2013). Teacher incentives and student achievement: Evidence from New York City public schools. Journal of Labor Economics, 31(2), 373-407. https://doi.org/10.1086/667757

Glewwe, P., Ilias, N., \& Kremer, M. (2010). Teacher incentives. American Economic Journal: Applied Economics, 2(3), 205-27. https://doi.org/10.1257/app.2.3.205

Goldstein, N. J., Cialdini, R. B., \& Griskevicius, V. (2008). A room with a viewpoint: Using social norms to motivate environmental conservation in hotels. Journal of consumer Research, 35(3), 472-482. https://doi.org/10.1086/586910

Grant, A. M. (2008). The significance of task significance: Job performance effects, relational mechanisms, and boundary conditions. Journal of applied psychology, 93(1), 108. https://doi.org/10.1037/0021-9010.93.1.108

Grissom, J. A., \& Loeb, S. (2017). Assessing principals' assessments: Subjective evaluations of teacher effectiveness in low-and high-stakes environments. Education Finance and Policy, 12(3), 369-395. https://doi.org/10.1162/EDFP_a_00210 
Holmstrom, B., \& Milgrom, P. (1991). Multitask principal-agent analyses: Incentive contracts, asset ownership, and job design. Journal of Law, Economics, \& Organization, 7, 24-52. https://doi.org/10.1093/jleo/7.special_issue.24

Jacob, B. A., \& Levitt, S. D. (2003). Rotten apples: An investigation of the prevalence and predictors of teacher cheating. The Quarterly Journal of Economics, 118(3), 843-877. https://doi.org/10.1162/00335530360698441

Kahneman, D., \& Knetsch, J. L. (1992). Valuing public goods: the purchase of moral satisfaction. Journal of Environmental Economics and Management, 22(1), 57-70. https://doi.org/10.1016/0095-0696(92)90019-S

Kamenica, E. (2012). Behavioral economics and psychology of incentives. Annu. Rev. Econ., 4(1), 427-452. https://doi.org/10.1146/annurev-economics-080511-110909

Larkin, I., Pierce, L., \& Gino, F. (2012). The psychological costs of pay-for-performance: Implications for the strategic compensation of employees. Strategic Management Journal, 33(10), 1194-1214. https://doi.org/10.1002/smj.1974

Lazear, E. P. (1995). Personnel economics. MIT press.

Lazear, E. P. (2003). Teacher incentives. Swedish Economic Policy Review, 10(2), 179-214.

Locke, E. A., \& Latham, G. P. (2002). Building a practically useful theory of goal setting and task motivation: A 35-year odyssey. American psychologist, 57(9), 705. https://doi.org/10.1037/0003-066X.57.9.705

Lunenburg, F. C. (2011). Self-efficacy in the workplace: Implications for motivation and performance. International Journal of Management, Business, and Administration, 14(1), 1-6.

Mellström, C., \& Johannesson, M. (2008). Crowding out in blood donation: was Titmuss right?. Journal of the European Economic Association, 6(4), 845-863. https://doi.org/10.1162/JEEA.2008.6.4.845

Mento, A. J., Locke, E. A., \& Klein, H. J. (1992). Relationship of goal level to valence and instrumentality. Journal of Applied Psychology, 77(4), 395. https://doi.org/10.1037/0021-9010.77.4.395

Muralidharan, K. (2012). Long-Term Effects of Teacher Performance Pay: Experimental Evidence from India. Society for Research on Educational Effectiveness.

Read, D., Loewenstein, G., \& Kalyanaraman, S. (1999). Mixing virtue and vice: Combining the immediacy effect and the diversification heuristic. Journal of Behavioral Decision Making, 12(4), 257. https://doi.org/10.1002/(SICI)1099-0771(199912)12:4<257::AID-BDM327>3.0.CO;2-6

Rogers, T., Goldstein, N. J., \& Fox, C. R. (2018). Social Mobilization. Annual Review of Psychology. https://doi.org/10.1146/annurev-psych-122414-033718

Rogers, T., Ternovski, J., \& Yoeli, E. (2016). Potential follow-up increases private contributions to public goods. Proceedings of the National Academy of Sciences, 113(19), 5218-5220. https://doi.org/10.1073/pnas.1524899113

Ryan, R. M., \& Deci, E. L. (2000). Intrinsic and extrinsic motivations: Classic definitions and new directions. Contemporary Educational Psychology, 25(1), 54-67. https://doi.org/10.1006/ceps.1999.1020

Seijts, G. H., \& Latham, G. P. (2000). The effects of goal setting and group size on performance in a social dilemma. Canadian Journal of Behavioural Science/Revue canadienne des sciences du comportement, 32(2), 104. https://doi.org/10.1037/h0087105

Tyack, D. B., \& Cuban, L. (1995). Tinkering toward utopia. Harvard University Press.

U.S. Bareau of Labor Statistics. (2018). More education: Lower unemployment, higher earnings. Retrieved from https://www.bls.gov/emp/education_pays_handout.pdf

Vohs, K. D., Mead, N. L., \& Goode, M. R. (2006). The psychological consequences of money. Science, 314(5802), 1154-1156. https://doi.org/10.1126/science.1132491

Vroom, V. (1964). Work and motivation (Human Relations Collection). New York: Wiley.

Watt, H. M. G., \& Richardson, P. W. (2015). Teacher Motivation. International Encyclopedia of the Social \& Behavioral Sciences (Second Edition), 64-71. https://doi.org/10.1016/B978-0-08-097086-8.26082-0

Willms, J. D. (2010). School Composition and Contextual Effects on Student Outcomes. Teachers College Record, 112(4), 1008-1037. 


\section{Copyrights}

Copyright for this article is retained by the author, with first publication rights granted to the journal.

This is an open-access article distributed under the terms and conditions of the Creative Commons Attribution license (http://creativecommons.org/licenses/by/4.0/). 